\title{
Localization of Alkaline Phosphatase and Osteopontin during Matrix Mineralization in the Developing Cartilage of Coccygeal Vertebrae*
}

\author{
Tomoyo SASAKI ${ }^{1}$, Norio AMIZUKA ${ }^{1 * *}$, Kazuharu IRIE $^{2}$, Sadakazu EJIRI ${ }^{1}$ and Hidehiro OzaWA \\ Department of Oral Anatomy ${ }^{1}$, Niigata University Faculty of Dentistry, Niigata; and Department of Oral Anatomy², \\ School of Dentistry, Health Sciences University of Hokkaido, Ishikari-Tobetsu, Japan
}

Received April 18, 2000

Summary. We observed the manner in which alkaline phosphatase (ALPase) and osteopontin were localized in the cartilage and intramembranous bone of coccygeal vertebrae during matrix mineralization, shedding considerable light on the manner in which they develop. In the cartilage matrix of coccygeal vertebrae, we observed the localization of ALPase activity in the boundary of the proliferative and the hypertrophic zones. Granular nodules of mineralization were consistently found in the boundary of both zones, and increased in size when close to the hypertrophic zone. While osteopontin was rarely present in the early stages of mineralization, its localization along the margins of mineralized matrices in the hypertrophic zone was prominent. In contrast to cartilage, mineralized nodules in the intramembranous bone in the mid-portion of the vertebra displayed osteopontin-immunoreactivity, indicating its early synthesis and subsequent accumulation to early-stage mineralized nodules. When blood vessels, accompanied by osteoblastic and osteoclastic cell populations, invaded the cartilage, osteopontin was localized in the lower region of the hypertrophic zone, despite its maintaining the localization of ALPase and early-stage mineralization. Thus, our investigation demonstrated ALPase activity consistent with early-stage mineralization in the cartilage matrix. However, the fact that osteopontinlocalization could not be pinpointed might account for its multifunctionality as concerns both the regulation of mineralization and the attachment of migrating osteogenic and osteoclastic cells to the mineralized matrix.

The process of endochondral ossification involves a clearly-defined series of events in which osteogenic and osteoclastic cells replace mineralized cartilage.
Cartilage rudiments form distinct regions referred to as resting, proliferative, and hypertrophic zones. Within erosion zones, vascular endothelial cells invade the hypertrophic zone, causing the collapse of incompletely-mineralized transverse partitions, and consequently permitting the invasion of osteoclast- and osteoblast-cell populations. In contrast to cartilaginous partitions, the longitudinal intercolumnar septae are well-mineralized, and serve as scaffolds of primary trabecular spicules, which are distributed uniformly in areas parallel to the longitudinal axis. Therefore, the longitudinal distribution of the mineralized cartilage matrix appears to be essential for the formation of the primary trabecular bone.

It seems likely that the mineralization process is regulated by a large number of matrix proteins and glycosaminoglycans. Among phosphoproteins, osteopontin is especially suited to the task of regulating mineralization because it so effectively inhibits both apatite formation and growth (Bosky et al., 1993; Hunter and GolberG, 1993). Osteopontin localizes chiefly in osteoid in vivo, whereas other proteins such as bone sialoprotein and $\alpha 2 \mathrm{HS}$-glycoprotein are present not in the osteoid but in completely mineralized bone matrix (MCKEE et al., 1993, 1995; MCKEE and NANCI, 1996). Osteopontin has been suggested as a bone matrix protein secreted in the early stages of bone matrix formation, as it is known to localize in the periphery of mineralized nodules, or, in the lamina limitans, where it can act to block excess mineralization (MARK et al., 1988).

In contrast to osteopontin, alkaline phosphatase (ALPase) hydrolyzes various phosphate esters, and is

*This work was supported in part by a Grant-in-Aid from the Ministry of Education, Science, Culture and Sports of Japan. **Norio AMIZUKA is a recipient of a grant from the Kato Memorial Bioscience Foundation. 
responsible for the production of inorganic phosphate. It was therefore thought to induce mineralization. In cartilage, ALPase activity has been detected on chondrocyte-cell surfaces (MATSUZAWA and AN. DERSON 1971; DE BERNARD et al., 1986), as well as those of osteoblasts (TAKAhashi 1972, PINERo et al. 1995; MoRRIS et al., 1992). It has been described as being localized on the cell-membranes of chondrocytes, and the basolateral cell membrane of osteoblasts, or in matrix vesicles secreted by osteoblasts and chondrocytes. ROBINSON (1921) suggested that it might hydrolyze organic phosphate ester, raising the concentration of local phosphate anions. FLEISCH and NEUMAN (1961) have provided a putative theory that ALPase removes pyrophosphate, which then permits hydroxyapatite crystal growth. Although the precise role of ALPase in bone mineralization is a matter of ongoing discussion, ALPase appears to be involved in the mineralization of cartilage and bone.

It is generally accepted that the first indication of the establishment of a center of ossification in a cartilage model is an enlargement of those chondrocytes residing in the middle portion of the hyaline cartilage shaft. This would be consistent with the enlargement of their lacunae at the expense of the intervening cartilage matrix. The matrix remaining in the region of the hypertrophic zone then becomes mineralized, and osteogenic potency of cells in the perichondrium covering the mid-portion of the shaft are subsequently activated. These cells then set about the process of intramembranous ossification. Coccygeal vertebrae, when observed from distal to proximal, provide for an easy understanding of the sequence by which cartilage develops, and therefore offer valuable evidence in chronologically-based investigations of ALPase- and osteopontin-localization during the matrix mineralization of cartilage and intramembranous bone. In the present study, we localized ALPase and osteopontin during the mineralization of cartilage and coccygeal vertebrae bone-matrices.

\section{MATERIALS AND METHODS}

\section{Tissue preparation}

Four-day-old ICR mice were anesthetized with diethyl ether, and perfused through the left ventricle by means of a 22 gauge needle with either $4 \%$ paraformaldehyde in $0.1 \mathrm{M}$ phosphate buffer $(\mathrm{pH} 7.4)$, or a mixture of $2 \%$ paraformaldehyde and $2.5 \%$ glutaraldehyde in $0.067 \mathrm{M}$ phosphate buffer. The animal tails were subsequently removed, and immersed in the same fixative for approximately $5 \mathrm{~h}$ at $4^{\circ} \mathrm{C}$. Some specimens were then demineralized with $10 \%$ EDTA solution and dehydrated with increasing concentrations of ethanol, prior to being embedded either in paraffin or Technovit 8100 (Heraeus Kulzer GmbH Wehrheim, Germany). Those specimens that we did not demineralize were post-fixed with $1 \% \mathrm{OsO}_{4}$ in 0.1 $\mathrm{M}$ cacodylate buffer ( $\mathrm{pH} 7.4$ ) for $3 \mathrm{~h}$ at $4^{\circ} \mathrm{C}$. Specimens were then dehydrated with ascending concentrations of acetone, and embedded in Epok (Polysciences, Inc., Warrington, PA) prior to transmission electron microscopic (TEM) observation (JEM-100 CX II, JOEL Ltd., Tokyo) at $80 \mathrm{KV}$.

\section{Triple-staining for osteopontin, ALPase and TRAPase in Technovit sections}

For osteopontin-immunodetection, Technovit sections were treated with $0.1 \%$ hydrogen peroxidase for 15 min, so as to inhibit endogenous peroxidase, and subsequently pre-incubated with $1 \%$ bovine serum albumin in phosphate-buffered saline (1\% BSA-PBS, pH 7.4) for 30 min at room temperature. The sections were incubated with goat anti-osteopontin at a dilution of 1:200 as described previously (IRIE et al., 1998), following incubation with secondary antibodies against goat Igs (Kirkegaard \& Perry laboratories Inc. Gaithersburg, MD). Visualization was performed using diaminobenzidine as a substrate. Subsequent double-staining of ALPase and tartrate-resistant acid phosphatase (TRAPase) by the Azo dye method (BuRSTONE, 1958) was done according to AMIZUKA et al (1997). In brief, for ALPase staining, sections were incubated with a mixture of $5 \mathrm{mg}$ of naphtol AS-BI phosphate (Sigma, St. Louis, MO) as a substrate and $18 \mathrm{mg}$ of fast blue RR salt (Sigma), diluted in $30 \mathrm{ml}$ $0.1 \mathrm{M}$ Tris- $\mathrm{HCl}$ buffer $(\mathrm{pH} 8.5)$ at $37^{\circ} \mathrm{C}$ for $30 \mathrm{~min}$. For subsequent TRAPase staining, the sections were incubated in a mixture of $8 \mathrm{mg}$ of naphtol AS-BI phosphate (Sigma) and $70 \mathrm{mg}$ of fast red violet salt (Sigma) and $50 \mathrm{mM} \mathrm{L}(+)$ tartaric acid ( $0.76 \mathrm{~g}$, Nacalai Tesque, Kyoto, Japan) diluted in $0.1 \mathrm{M}$ sodium acetate buffer $\left(\mathrm{pH} \mathrm{5.0)}\right.$ for $30 \mathrm{~min}$ at $37^{\circ} \mathrm{C}$. Sections showed slight counter-staining with methylgreen.

\section{Von Kossa staining on Technovit sections}

Undemineralized Technovit sections were incubated with an aqueous solution of 5\% silver nitrate (Kolima Chemical Co. Ltd, Japan) for $60 \mathrm{~min}$ at room temperature under sunlight until they took on a darkbrown color. Following a DW rinse, the sections were incubated with a $5 \%$ sodium thiosulfate solution (Wako Pure Chemical Industries, Japan) for $5 \mathrm{~min}$. The sections showed faint counterstaining to toluidine blue. 
Immunoelectron microscopic observation of osteopontin

Caudal specimens obtained as above were demineralized in $4.13 \%$ EDTA for 4 days and embedded in LR white (London Resin Company, Ltd, Berkshire, UK). Ultrathin sections of LR white mounted on nickel grids were incubated with goat anti-osteopontin diluted at a rate of $1: 200$ with $1 \%$ BSA-PBS for $1 \mathrm{~h}$ at room temperature. The sections were then washed with PBS and subsequently incubated with colloidal gold-conjugated anti-goat Igs (Sigma, St. Louis, MO) at a dilution of $1: 100$ with $1 \%$ BSA-PBS for $1 \mathrm{~h}$ prior to electron microscopic observation (JEM 100 CX II microscope, JOEL Ltd., Tokyo, Japan) operated at 80 $\mathrm{kV}$.

\section{In situ hybridization for osteopontin gene}

In situ hybridization was performed according to procedures described previously (AMIzUKA et al., 1996). De-waxed paraffin sections were treated with $4 \%$ paraformaldehyde in $0.1 \mathrm{M}$ phosphate buffer for $15 \mathrm{~min}$ and then with proteinase $\mathrm{K}(10 \mu \mathrm{g} / \mathrm{ml})$ in 10 $\mathrm{mM}$ Tris- $\mathrm{HCl}(\mathrm{pH} 8.0)$ at $37^{\circ} \mathrm{C}$ for $10 \mathrm{~min}$. They were then reincubated for $10 \mathrm{~min}$ with $0.2 \mathrm{M} \mathrm{HCl}$. At this point, the sections were incubated for a period of 10 min with $0.25 \%$ acetic anhydride in $0.1 \mathrm{M}$ triethanolamine ( $\mathrm{pH} 8.0$ ). Sense and antisense digoxigeninlabeled cRNA probes were obtained by transcription from rat osteopontin cDNA in pGEM3Z (Promega, Madison, WI). A hybridization mixture composed of $50 \%$ formamide, $10 \mathrm{mM}$ Tris- $\mathrm{HCl}(\mathrm{pH} 7.6), 200 \mu \mathrm{g} / \mathrm{ml}$ tRNA, $1 \times$ Denhardt's solution, $10 \%$ dextran sulfate, $600 \mathrm{mM} \mathrm{NaCl}, 0.25 \%$ SDS, and $1 \mathrm{mM}$ EDTA was preheated for $10 \mathrm{~min}$ at $90^{\circ} \mathrm{C}$. Each cRNA was adjusted to a concentration of $0.1-1.0 \mu \mathrm{g} / \mathrm{ml}$. The mixture was denatured by heating at $90^{\circ} \mathrm{C}$ for $2-3 \mathrm{~min}$ before application to the sections. Hybridization was performed overnight at $48^{\circ} \mathrm{C}$. After hybridization, sections were washed with $50 \%$ formamide in $2 \times \mathrm{SSC}$ at $50^{\circ} \mathrm{C}$ for $30 \mathrm{~min}$, and treated at $37^{\circ} \mathrm{C}$ with a solution of 10 $\mathrm{mM}$ Tris- $\mathrm{HCl}(\mathrm{pH} 8.0), 0.5 \mathrm{M} \mathrm{NaCl}$, and $1 \mathrm{mM}$ EDTA (TNE). Non-specific binding of probes was reduced by RNase A treatment $\left(20 \mu \mathrm{g} / \mathrm{ml}\right.$ in TNE) at $37^{\circ} \mathrm{C}$ for 30 min. For immunodetection of digoxigenin-labeled probes, sections were pre-incubated with a $2 \%$ blocking agent and incubated for 45-60 min with alkaline phosphatase-conjugated sheep anti-digoxigenin antibody at a dilution of $1: 1000$. Visualization was performed using nitroblue tetrazolium salt and 5-bromo4-chloro-3-indolylphosphate.

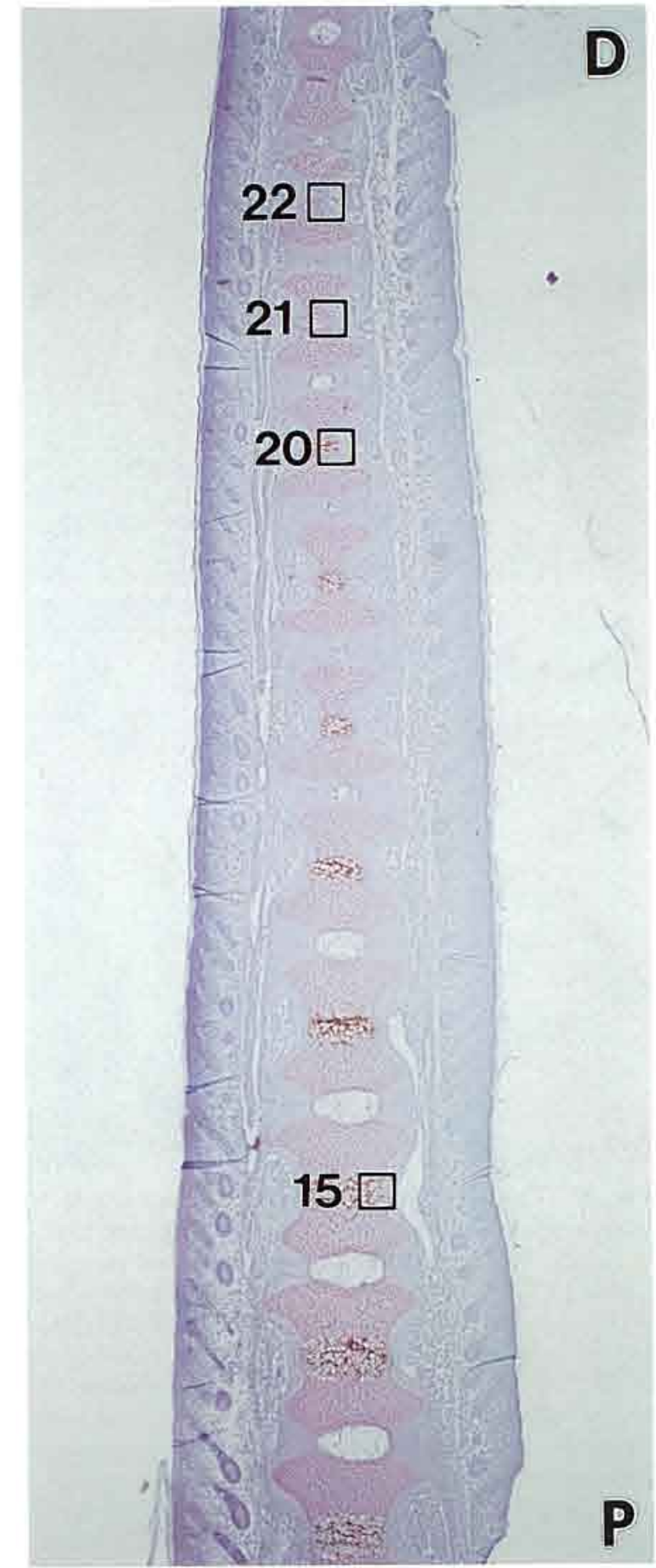

Fig. 1. Light microscopy reveals sequentially-developed coccygeal vertebrae when observed from the distal $(D)$ to the proximal $(P)$ regions in the 4 -day-old mouse. Squares indicate $22 \mathrm{nd}, 21$ st, 20 th and 15 th coccygeal vertebrae of the tail. 

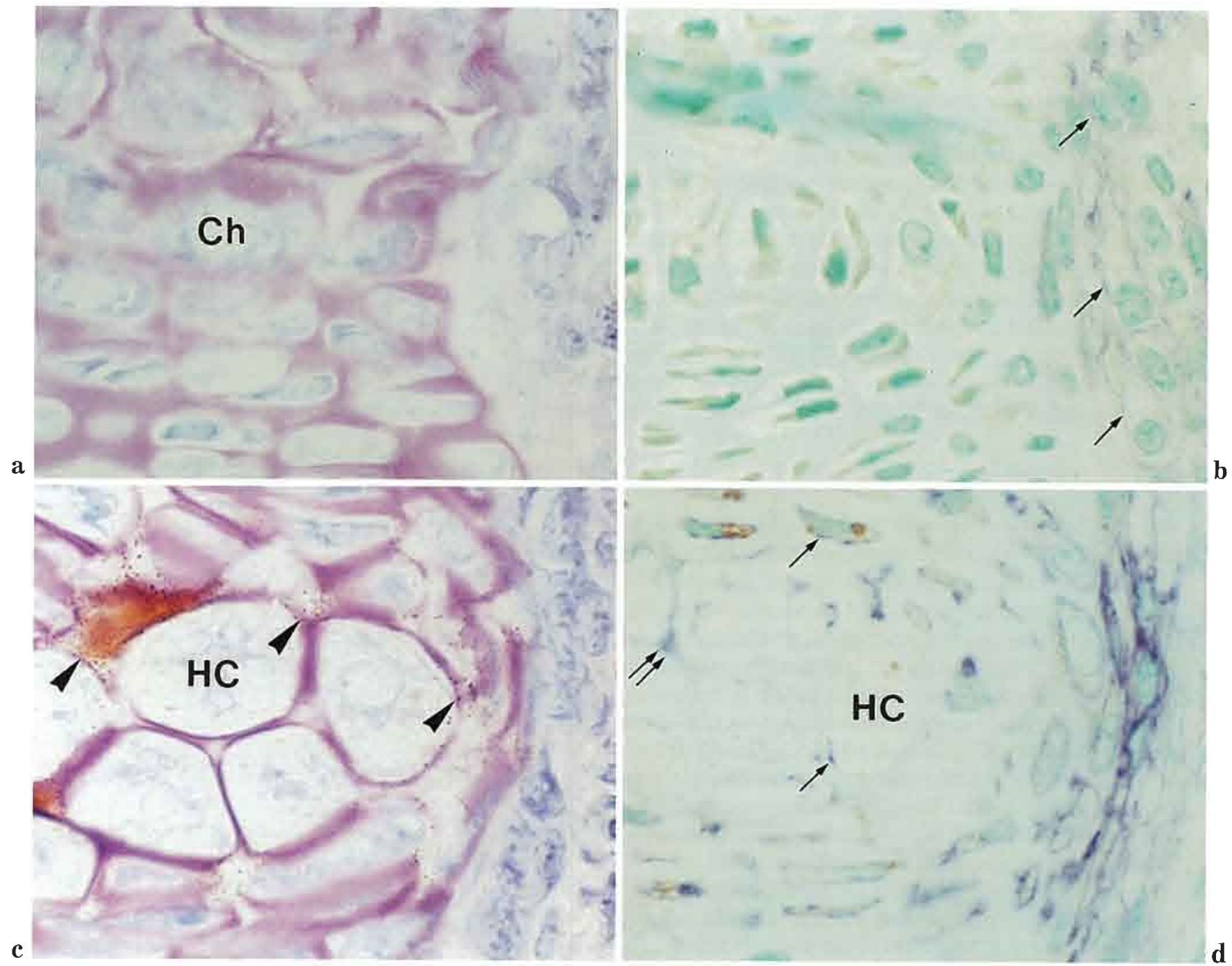

Fig. 2. The localization of von Kossa staining (a, $\mathbf{c}, \mathbf{e}, \mathbf{g})$ and ALPase, TRAPase and osteopontin (b, d, f, h) in the coccygeal vertebrae. The upper $(\mathbf{a}, \mathbf{b})$ and lower panels $(\mathbf{c}, \mathbf{d})$ show the 22 nd and 21 st vertebrae, respectively. a and b. The 22nd caudal vertebra did not reveal hypertrophic chondrocytes nor mineralization in the cartilage. Cells in region of the intramembranous ossification display ALPase activity on their cell membranes (arrows). c. In the 21st vertebra, chondrocytes are hypertropied, and accumulations of granular stainining of von Kossa (arrowheads) are observed in the cartilage matrix in the vicinity of the hypertrophic chondrocytes. d. ALPase activity is detected on cell membranes (arrows) of chondrocytes in the lower region of the proliferative zone and in the hypertrophic zone. ALPase is also seen in the inter-territorial region (double arrow) of these chondrocytes. Osteopontin immunoreactivity (brown color) is seen in chondrocytes. e. Note no von Kassa staining in the matrix adjacent to the periosteum. Broad and uniform stain of von Kossa is found in the hypertrophic zone, but the granular staining (arrowheads) is seen in the area of the intramembranous ossification in the 20th caudal cartilage. f. Osteopontin indicated by the brown color (arrows in black and white) is present in the inter-teritorial region of the cartilage matrix. ALPase (small arrous) and osteopontin (arrowhead) are localized in the thin layer adjacent to the ALPase-positive osteogenic cells. g. In the 15th coccygeal vertebra, the matrices of the hypertrophic zone are entirely mineralized. $\mathbf{h}$. TRAPase positive osteoclasts $(O C)$ indicated in red are observed close to the periosteal collar, and osteopontin is localized in the margines (arrows) of cartilage matrices. $C h$ chondryocyte, $H C$ hypertrophic chondrocyte, $O B$ osteoblast. $\times 370$ 


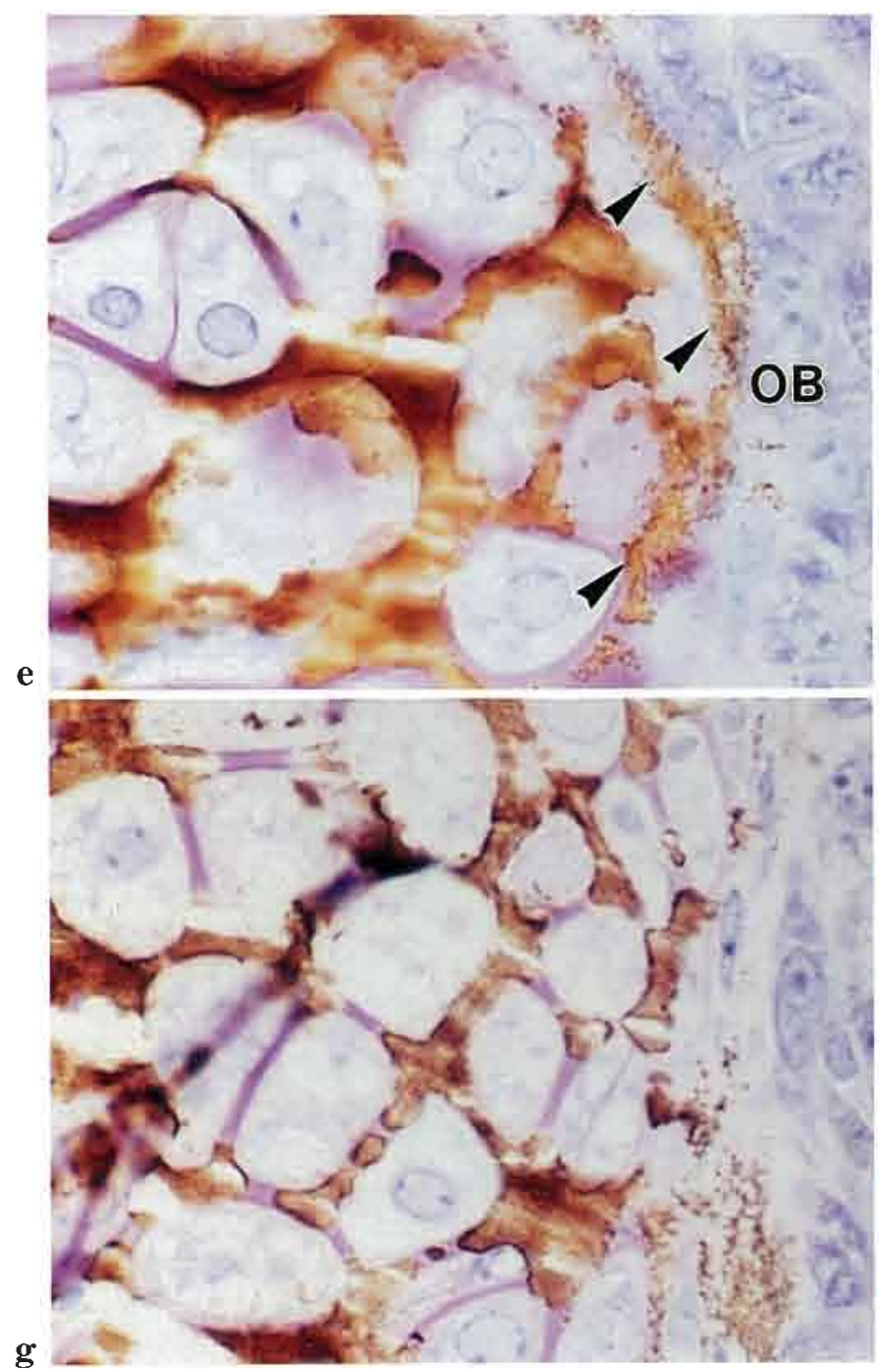

$\mathrm{g}$

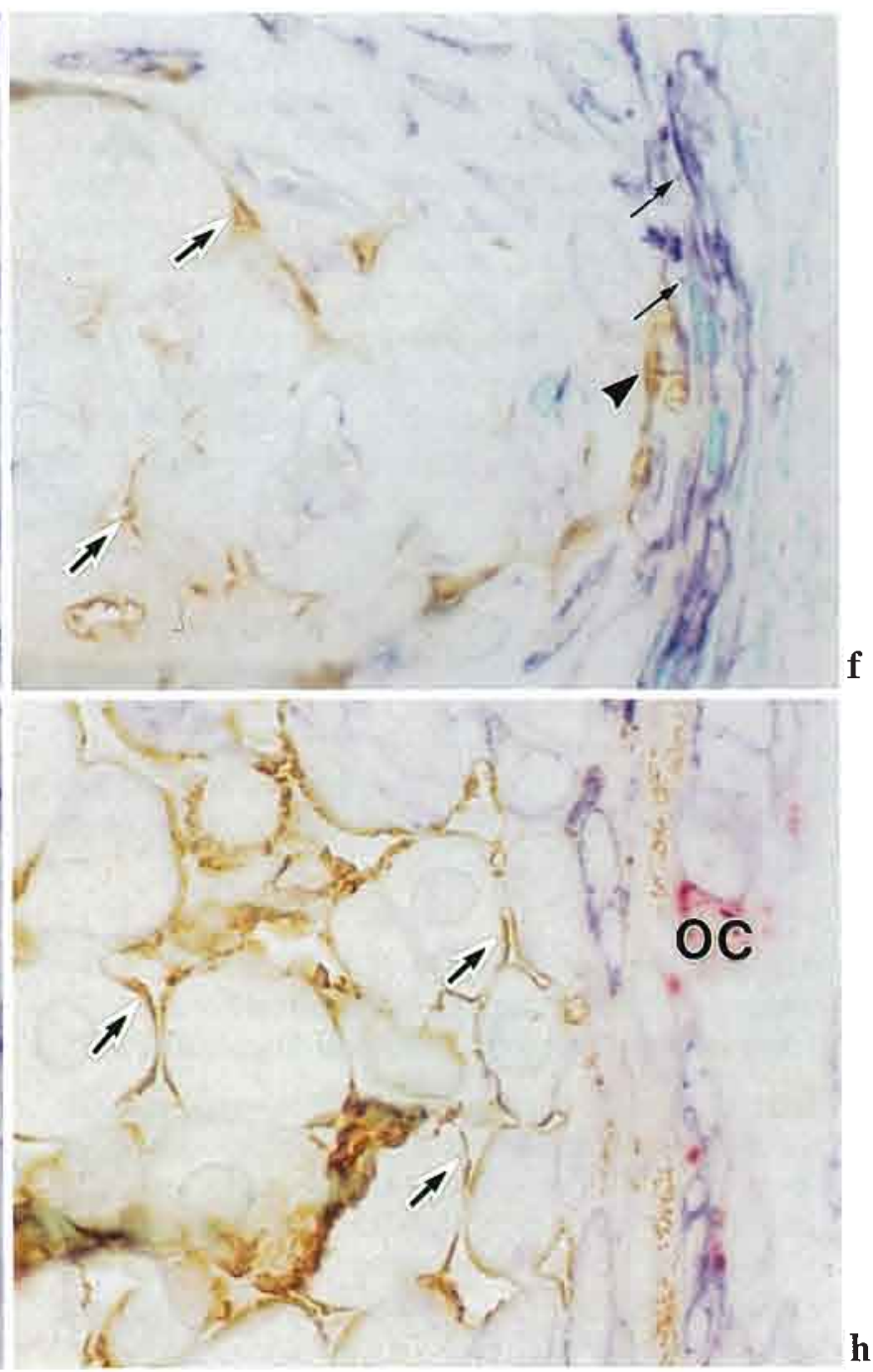

Fig. 2 e-h. Legend on the opposite page.

\section{RESULTS}

The localization of ALPase and osteopontin in mineralized cartilage and intramembranous bone matrices in developing coccygeal vertebrae

When coccygeal vertebrae were observed from the distal to the proximal, the sequence in which cartilage develops and endochondral bone subsequently forms could be clearly distinguished (Fig. 1). We have examined 4-day-old 22nd, 21st, 20th, 15th and 10th caudal vertebrae, for the purpose of localizing the position of ALPase and osteopontin during mineralization.

In the 22nd caudal vertebra, where chondrocytes had yet to differentiate into hypertrophic cells, there was no evidence of either mineralization or ALPase activity in the cartilage matrix (Fig. 2a, b). Although cells covering the mid-portion of vertebral cartilage displayed ALPase activity on their cell membranes, no mineralization was seen in the adjacent extracellular matrix. In the 21st coccygeal vertebra, cell membranes of chondrocytes in both the hypertrophic zone and the lower region of the proliferative zone displayed ALPase activity (Fig. 2c, d). ALPase was also detected in the inter-territorial region of cartilage matrix of these chondrocytes. At this stage, granular structures positive to von Kossa staining, and therefore indicative of a mineralized matrix, were observed in cartilage in the vicinity of hypertrophic chondrocytes. These structures nearly overlapped the extracellular ALPase-localization. 
Though osteopontin-immunoreactivity was seen in chondrocytes in the lower region of the proliferative zone, none was detected in the cartilage matrix. By this stage, no mineralization could be detected in areas of intramembranous ossification. In the hypertrophic zone of the 20th caudal cartilage, cartilage matrices were broadly mineralized with some fenestration, with osteopontin immunoreactivity evident in the periphery of mineralized matrices (Fig. 2e, f). The accumulation of von Kossa staining-positive granular structures identical to mineralized nodules was found in the thin layer of bone covering the mid-shaft of vertebrae, which is referred to as the periosteal bone collar (MAXIMOW, 1910), concurrent with the localization of ALPase activity and osteopontin immunoreactivity. When TRAPase-positive osteoclasts were observed in the region of intramembranous bone formation, the matrices of the hypertrophic zone were completely mineralized by this time (Fig. 2g, h). Osteopontin immunolocalization was restricted to the mineralized walls of cartilage lacunae.

\section{Ultrastructural observation of osteopontin immunolocalization during mineralization of coccygeal cartilage and periosteal bone collar}

Electron microscopic observations showed mineralized nodules accumulated in the cartilage matrix at the boundary between the proliferative and the hypertrophic zones (Fig. 3a). Immuno-gold particles indicative of osteopontin immunoreactivity did not localize on electron dense structures, identical to the mineralized nodules (Fig. 3b). In observing the hypertrophic zone, we noted that the cartilage matrix was entirely mineralized, while the superficial layer of cartilage lacunae was immunoreactive for osteopontin (Fig. $4 \mathrm{a}, \mathrm{b}$ ). In contrast to cartilage, intramembranous bone revealed numerous mineralized nodules among collagen fibrils (Fig. 5a), and osteopontin immunoreactivity was clearly evident in these nodular structures (Fig. 5b).

\section{Alternative localization of osteopontin in cartilage subjected to vascular invasion}

We next compared the localizations of ALPase and osteopontin in association with matrix-mineralization, according to chondrocyte-differentiation, in the 20 th and the 10th caudal vertebrae (Fig. 6); the 20th vertebra resisted invasion by osteogenic and osteoclastic cell populations (Fig. 6a), whereas the 10th vertebra revealed branching blood vessels extending into internal cartilage lacunae, forming periosteal buds (Fig. 6d). Observing the boundary between the proliferative and the hypertrophic zones of the 20th coccygeal cartilage revealed the presence of primary mineralization expanding toward the hypertrophic zone (Fig. 6b). ALPase was seen in the inter-territorial regions from the lower proliferative to the hypertrophic zone (Fig. 6c). In contrast, osteopontin was detected in the upper region of the hypertrophic zone, especially localizing at the margins of mineralized matrices (Fig. 6c). When the area of the 10th coccygeal cartilage-segment (Fig. 6d) was subjected to vascular invasion, ALPase-distribution and mineralization were seemingly unaffected with localization at the boundary between proliferative and hypertrophic zones remaining unchanged (Fig. 6e, f). However, osteopontin immunoreactivity was restricted to the lower region of the hypertrophic zone (Fig. 6f). Consistent with the protein localization, in situ hybridization displayed a tendency to reduce the overall localization of osteopontin mRNA from its broad base throughout the hypertrophic zone (Fig. 7a) to just the lower region (Fig. 7b).

\section{DISCUSSION}

Following cartilage mineralization, endochondral bone formation is achieved by vascular invasion accompanied by a series of cellular events among osteogenic and osteoclastic cell populations. The longitudinal array of mineralized cartilaginous septae serves as a scaffold for subsequent bone matrix deposition, resulting in the formation of primary trabecular bone. The all-important first step in the process of endochondral bone formation, therefore, appears to be mineralization of the cartilage matrix. For this reason, we employed coccygeal vertebrae obtained from 4-day-old post-natal mice, since they would provide a clear record of the various stages of cartilage development. In this study, we employed Technovit embedding material in order to display the 3-part (ALPase-/TRAPase-enzyme histochemistry, and osteopontin immunoreactivity) staining process on undemineralized sections.

Previous reports described ALPase activity on cell membranes of chondrocytes and in inter-territorial regions of peripheral matrix (MATSUZAWA and ANDERSON 1971; DE BERNARD et al. 1986). We have demonstrated how the caudal cartilage matrix shows extracellular ALPase activity earlier than in the matrix covering the mid-portion of the vertebrae, which was not at all bone matrix yet, but would become periosteal bone in the future. Our study indicates that extracellular ALPase-probably identical 

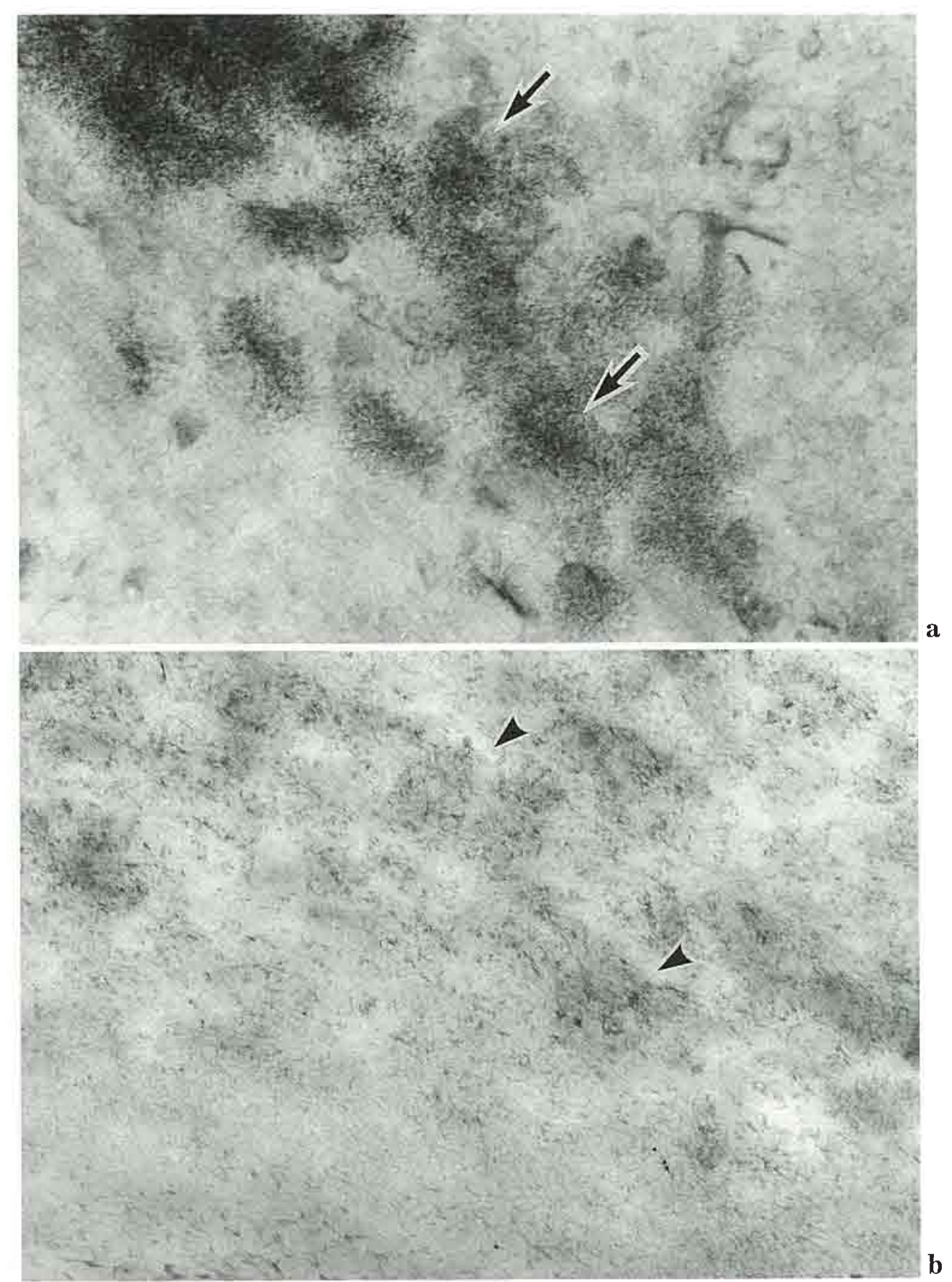

Fig. 3. An electron microscopic view of mineralized nodules (arrows) gathered in the cartilage matrix which is located at the boundary between the proliferative and the hypertrophic zones (a). Immuno-gold particles for osteopontin immunoreactivity are not localized on the electron dense structures (arrowheads, b). a: $\times 35,000, \mathrm{~b}: \times 40,000$ 


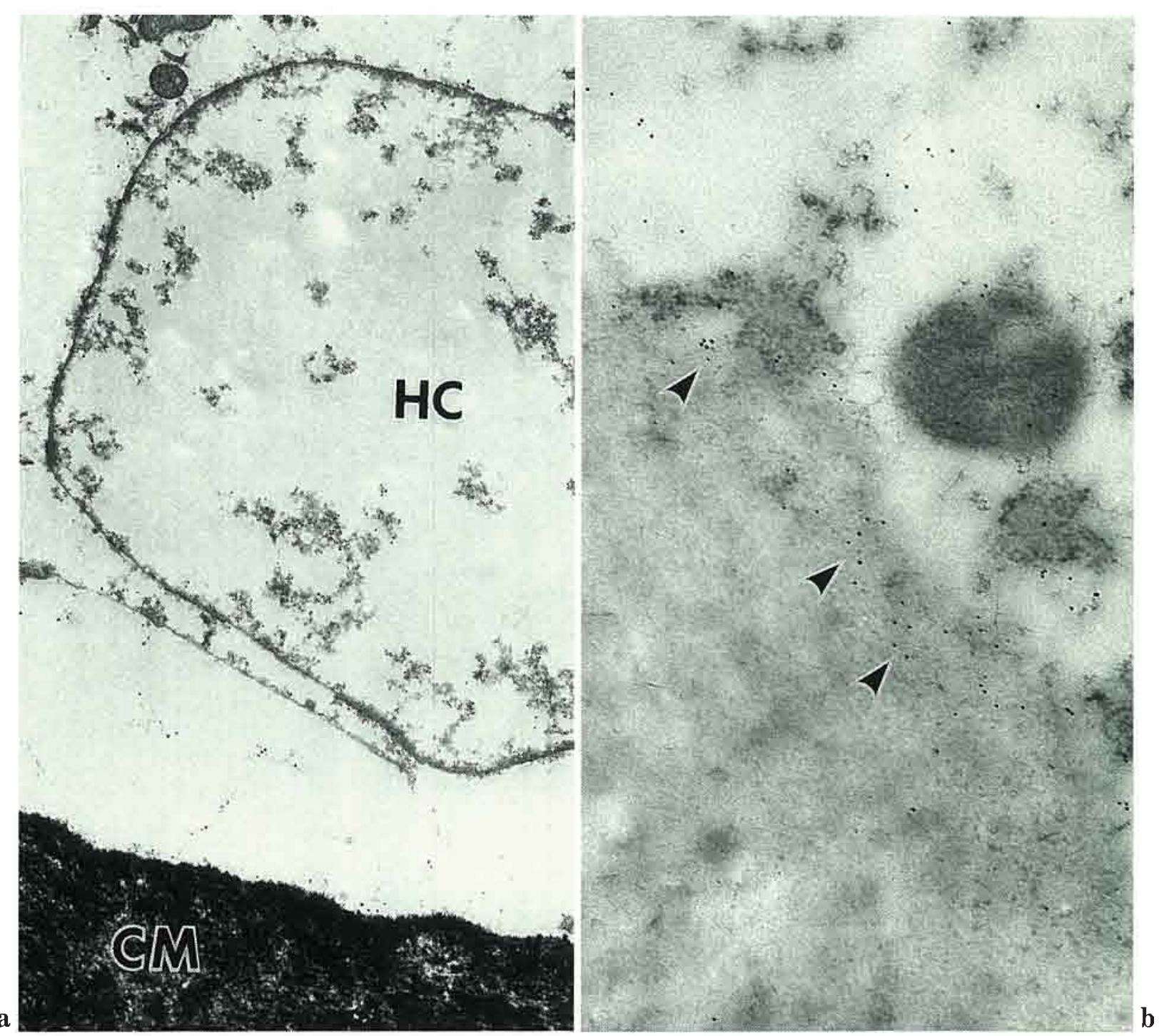

Fig. 4. In the hypertrophic zone, the cartilage matrix $(C M)$ is well-mineralized facing the hypertrophic chondrocyte $(H C, \mathbf{a})$, and the superficial layer of the cartilage matrix contains gold particles (arrowheads) indicative of osteopontin, while the inner regions of the cartilage matrix do not (b). a: $\times 10,000, \mathrm{~b}: \times 40,000$

to matrix vesicles and mineralized nodules-rather than that on cell membranes plays an important role in mineralization.

In situ hybridization and immunohistochemical examinations showed osteopontin in the hypertrophic zone of the coccygeal cartilage. Osteopontin would normally be present mainly in osteoid and especially the mineralized foci, whereas other proteins including bone sialoprotein are present in bone matrix that has entirely mineralized (MCKEE et al., 1995). Among the noncollagenous proteins, the distribution of osteopontin in mineralized tissues is unique in several impor- tant aspects. As previously demonstrated (IRIE et al., 1998, MCKEE et al., 1993), we have used the immunogold technique to localize osteopontin accumulated in the mineralized nodules of intramembranous bone. As McKeE et al. $(1993,1995,1996)$ have stated, evidence of the accumulation of osteopontin at cement lines in mineralized foci of organic matrix among the collagen fibrils and in lamina limitans has indicated that osteopontin may act as an inhibitor for mineralization in a poorly-mineralized matrix. In addition, it has been reported to be a potent inhibitor of both de novo apatite formation and elongation (BOSKY et al., 

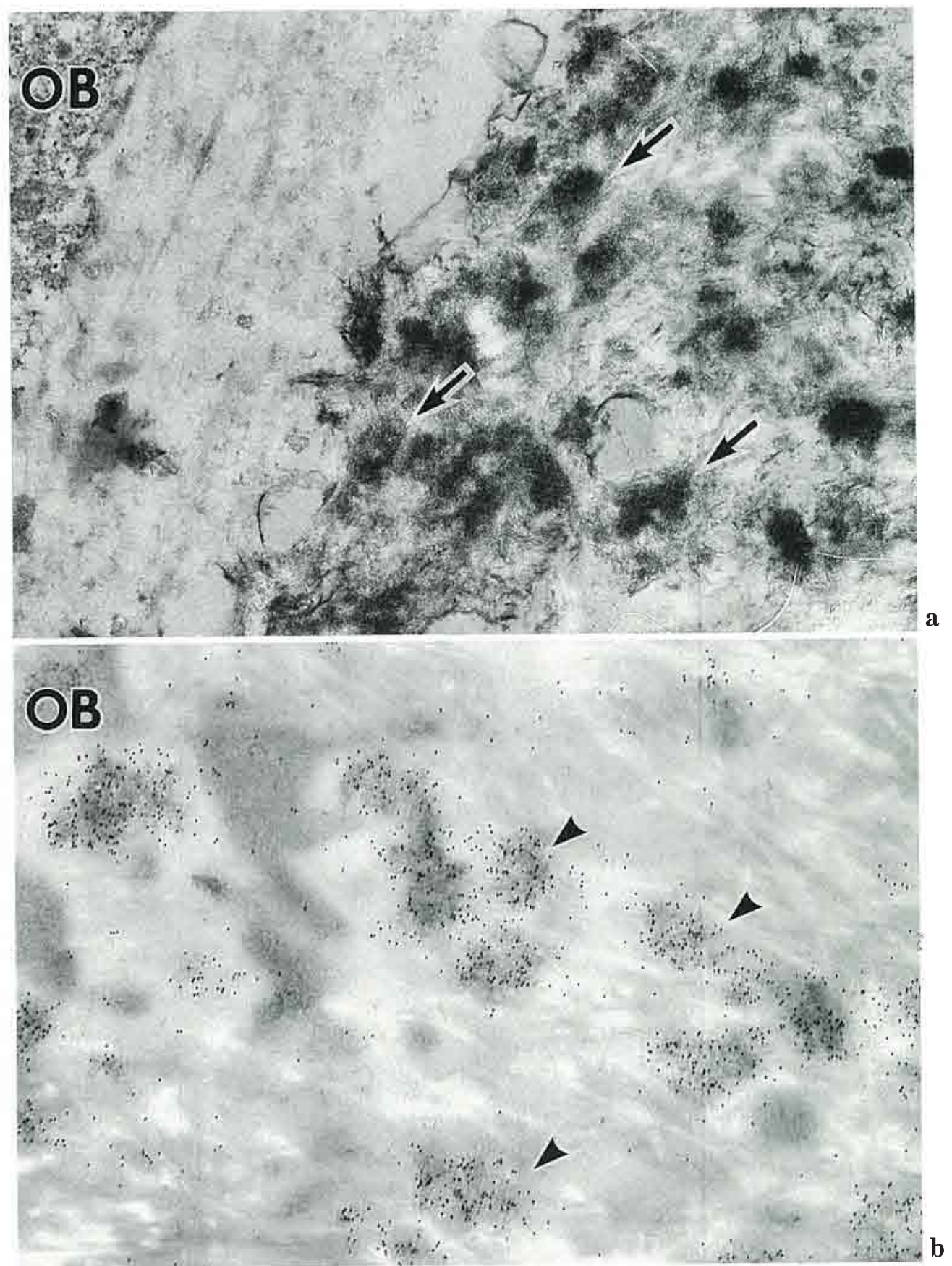

Fig. 5. Bone matrix in the intramembranous ossification covering the mid-portion of the coccygeal vertebrae reveals numerous electron-dense mineralized nodules (arrows, a), and osteopontin immunoreactivity indicated by gold particles is intense in these nodular structures (arrowheads, b). $O B$ osteoblast. a: $\times 32,000, \mathrm{~b}: \times 31,000$ 


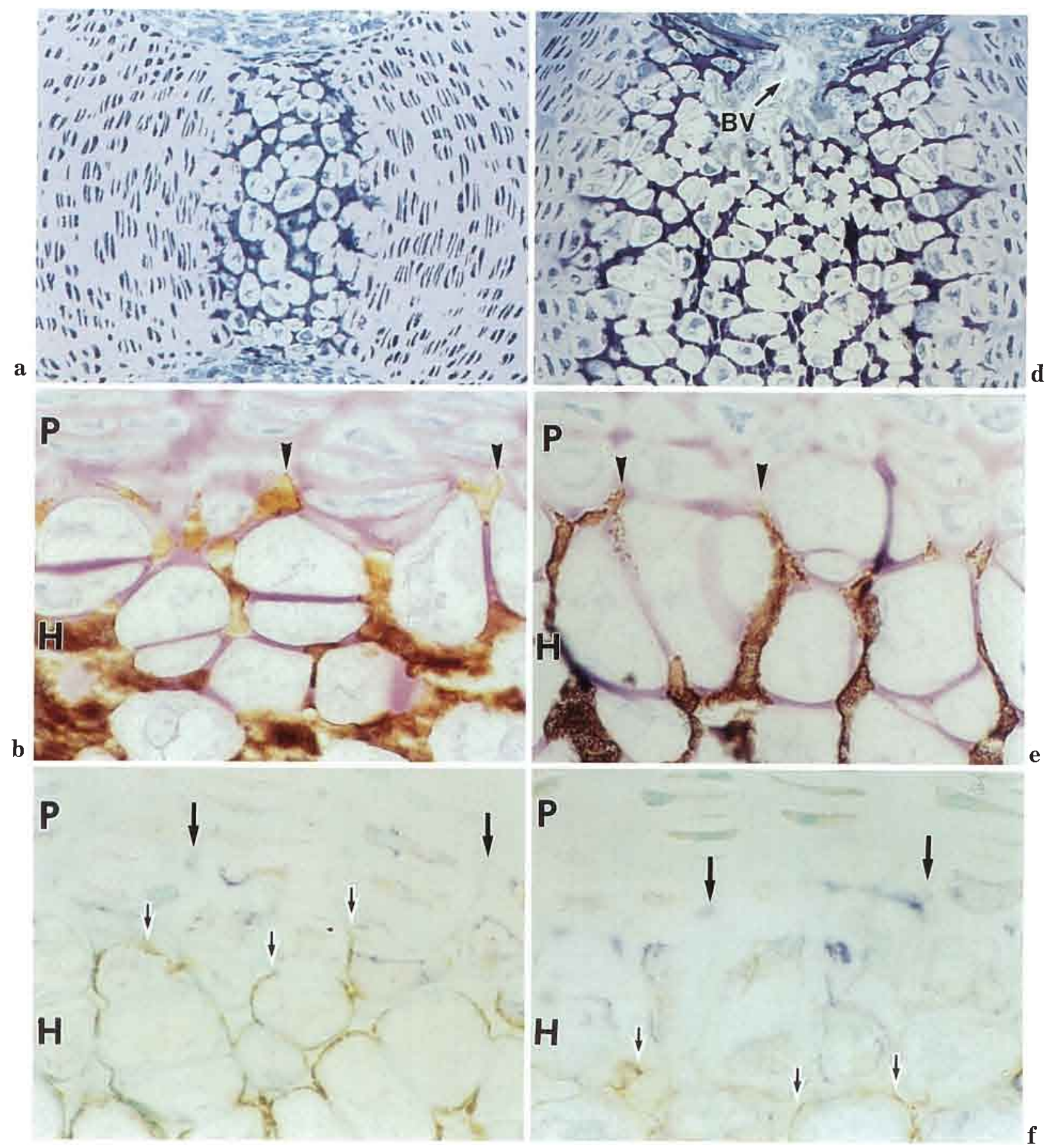

Fig. 6. The localization of ALPase and osteopontin during matrix-mineralization in vertebular cartilages with (10th vertebra, right panels $\mathbf{d}-\mathbf{f}$ ) or without (20th vertebra, left panels a-c) vascular invasion. The 20th vertebra shows cartilage rudiment without vascular invasion (a), but the 10th vertebra reveals perosteal but including blood vessles (arrow d). At the boundary between the proliferative and the hypertrophic zones of the 20th coccygeal cartilage, the early stage of mineralization (arrowheads) is found, expanding in size when close to the hypertrophic zone (b). ALPase (black arrows) is seen in the inter-territorial region, persisting from the lower proliferative zone up to the hypertrophic zone (c). Osteopontin (small arrows) is detected in the upper region of the hypertrophic zone, especially localizing at the margins of mineralized matrices (c). In cartilage subjected to vascular invasion in the 10th coccygeal vertebra (d), von Kossa stain (arrowheads) displayes the mineralization remaining at the initiation of the boundary of the proliferative and the hypertrophic zones as well as before vascular invasion (e). Osteopontin immunoreactivity (small arrows) is restricted to the lower region of the hypertrophic zone (f). $P$ proliferative zone, $H$ hypertrophic zone, $B V$ blood vessel. a, d: $\times 100$, b, e: $\times 290$, c, f: $\times 290$ 
Fig. 7. In situ hybridization displays the localization of osteopontin mRNA (brown color) in the entire hypertrophic zone of the 20th vertebra (a), whereas after vasculr invasion, the hybridization signal is localized predominantly in the lower region of the hypertrophic zone (b). $P$ proliferative zone, $H$ hypertrophic zone, $B$ bone. a, b: $\times 160$

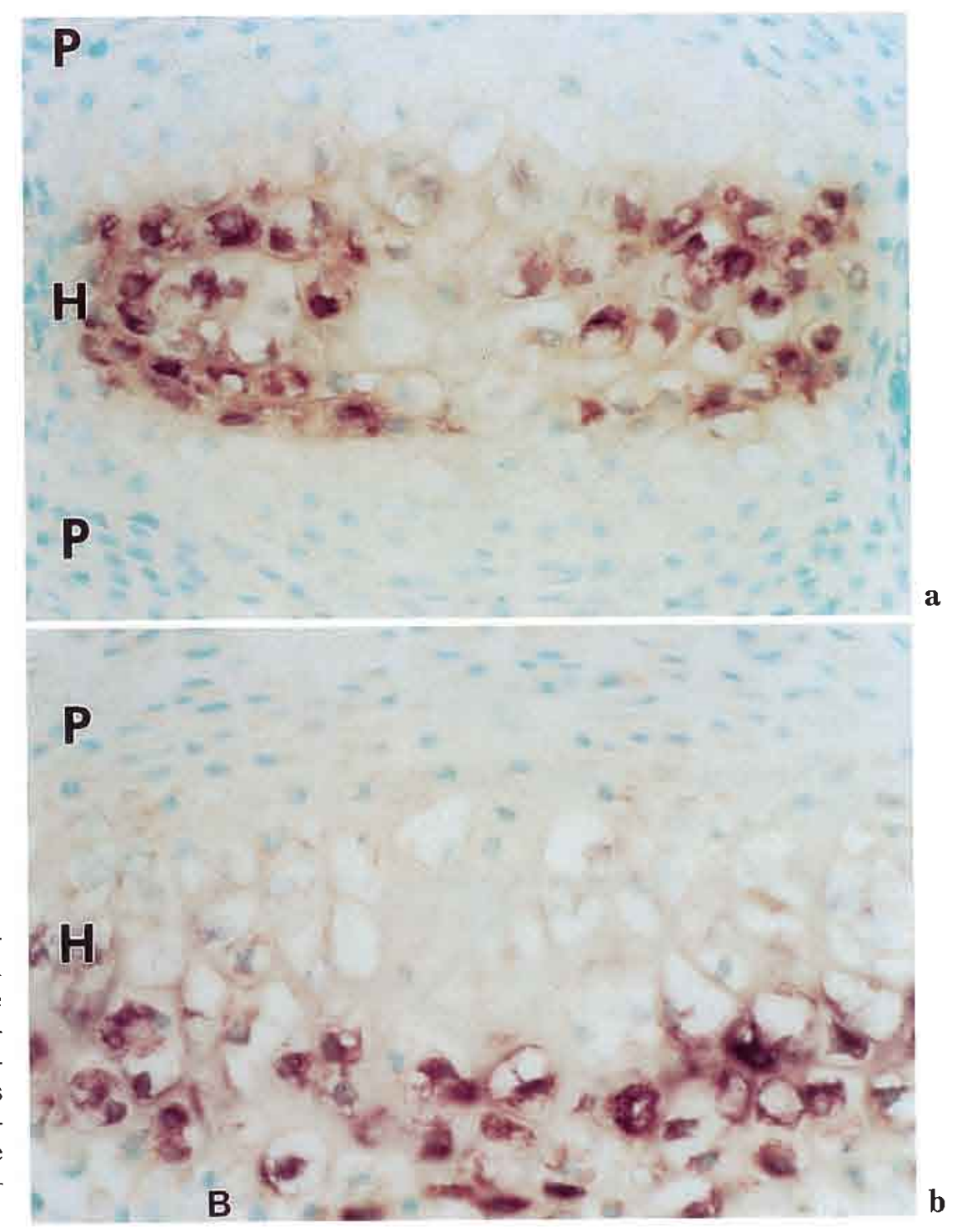

1993, Hunter and GOLBERG, 1993). Unlike the bone matrix, osteopontin was hardly detected in mineralized cartilage nodules, hinting at the possibility that abundant cartilagious proteoglycans-including aggrecan-may regulate the initial growth of mineralization. Nevertheless, it is likely that osteopontin is localized at the margins and/or superficial layer of the mineralized matrix in the hypertrophic zone, and therefore suggests that osteopontin could participate in the regulation of cartilage mineralization and subsequent growth.

It is noteworthy that, when cartilage was subjected to vascular invasion, osteopontin mRNA and protein localization were restricted to the lower region of the hypertrophic zone, a situation thought to result from delayed hypertrophic chondrocytes' gene-expression. NoRUMA and his colleagues revealed osteopontin expression in the terminally-differentiated hypertrophic chondrocytes of the adult growth plate cartilage (NAKASE et al., 1994). In our study employing neonatal mice, when cartilage was not subjected to vascular invasion, osteopontin was expressed in the entire hypertrophic zone. However, consistent with NAKASE's observations, once vascular invasion occurred, its expression was restricted to the lower region of the hypertrophic zone. Osteopontin is known to participate in the early, formative process of osteogenesis, through the attachment of osteoblasts 


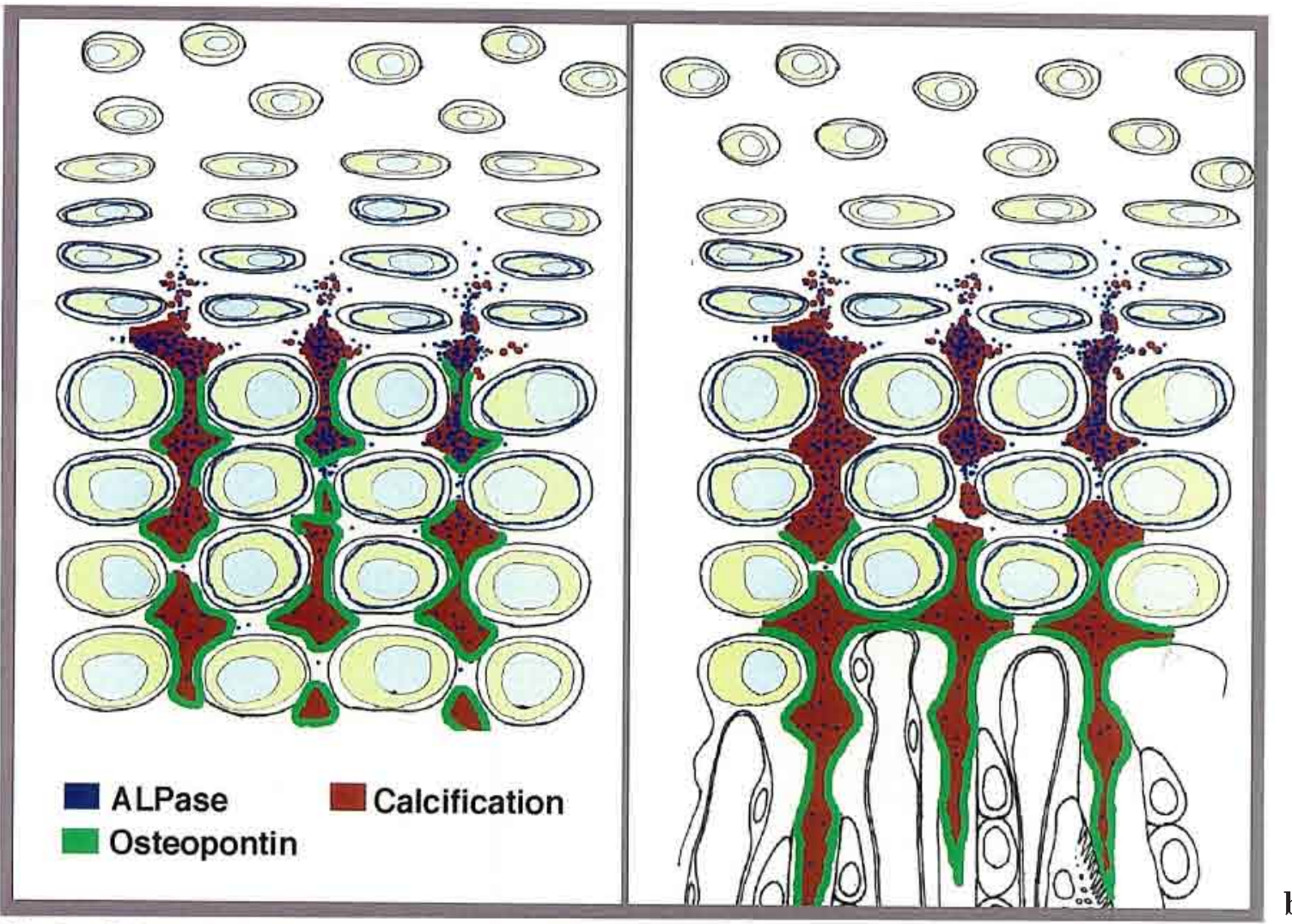

Fig. 8. Schematic design summarizing results in this study. ALPase and early stage mineralization were detected along the boundary between the proliferative and the hypertrophic zones, whereas osteopontin was localized almost in the hypertrophic zone (a). Alternatively, once vascular invasion occurs, osteopontin is restricted to the lower region of the hypertrophic zone (b).

to the extracellular matrix that they are depositing, be involved in attachment of osteoclasts as well, and act to regulate crystal elongation. According to OLDBERG et al. (1986), a rat osteoblast cell line (ROS 17/2.8) attached and spread over osteopontin-coated surfaces. However, this bonding activity was effectively prevented by the administration of exogenous RGD-bearing peptides, which may account for the fact that the RGD sequence in osteopontin takes part in interaction with $\alpha \mathrm{v} \beta 3$ integrins, resulting in a cell-to-matrix attachment (REINHOLT et al., 1990; FLORES et al., 1992; Ross et al., 1993; HyNES, 1992). Taken together, the presence of osteopontin in the superfical layer of the mineralized cartilage matrix in the hypertrophic zone points to a role in the promotion of cellular attachment and spreading via interaction with cell-surface integrins of migrating osteoblastic and osteoclastic cells, rather than its acting as an inhibitor of mineralization. Of special interest is the fact that osteopontin was reported to serve as a potent factor for angiogenesis in tumor-metastatic lesions (SHIJUBo et al., 1999; LIAW and CRAWFORD, 1999). Therefore, in addition to its well-known physiological effects, osteopontin may act as an inducer of vascular migration, and may account for the spatially-limited localization of osteopontin to the lower region of the hypertrophic zone, which could be initially exposed to migrating endothelial cells. Recently, vascular endothelial growth factor (VEGF) has been reported to be expressed in the hypertrophic zone during endochodral bone formation (GERBER et al., 1999). Osteopontin and VEGF may cooperate in the task of vascular invasion during this time. Further investigations will be necessary regarding the cellular mechanisms of vascular invasion into the cartilage.

In summary, we have demonstrated the spatial and temporal localization of ALPase, mineralization, and osteopontin in cartilage rudiments, ALPase and early stage mineralization were detected along the boundary between the proliferative and the hypertrophic zones, whereas osteopontin was localized almost 
exclusively in the hypertrophic zone. Alternatively, once vascular invasion occurs, osteopontin is restricted to the lower region of the hypertrophic zone. Osteopontin may act as both a regulator for mineralization, as has been suggested, but it could function as an inducer of vascular invasion and the subsequent attachment of migrating osteoblastic and osteoclastic cells.

\section{REFERENCES}

Amizuka, N., A. C. Karaplis, J. E. Henderson, H. Warshawsiky, M. L. Lipman, Y. Matsuki, S. EJIRI, M. Tanaka, N. Izumi, H. Ozawa and D. Goltzman: Haploinsufficiency of parathyroid hormone-related peptide (PTHrP) results in abnormal postnatal bone development. Devel. Biol. 175: 166-176 (1996).

amizuka, N., N. Takahashi, N. Udagawa, T. Suda and H. OZAWA: An ultrastructural study of cell-cell contact between mouse spleen cells and calvaria-derived osteoblastic cells in a co-culture system for osteoclast formation. Acta Histochem. Cytochem. 30: 351-362 (1997).

De Bernard, B., P. Bianco, E. Bonucci, M. Costantini, G. C. Lunazzi, P. Martinuzz, C. Modricky, L. Moro, E. Panfili, P. Pollesello, N. Stagni and F. Vittur: Biochemical and immunohistochemical evidence that in cartilage an alkaline phosphatase is a $\mathrm{Ca}^{2+}$-binding glycoprotein. J. Cell Biol. 103: 1615-1623 (1986).

Bosky, A. L., M. Maresca, W. Ullrich, S. B. Doty, W. T. Butler and C. W. Prince: Osteopontin-hydroxyapatite interactions in vitro: Inhibition of hydroxyapatite formation and growth in a gelatin-gel. Bone Miner. 22: 147-159 (1993).

Burstone, M. S.: Histochemical demonstration of acid phosphatase with naphthol AS-phospahte. J. Nat. Cancer Inst. 21: 523-539 (1958).

Fleish, H. and W. F. Neuman: Mechanisms of mineralization: role of collagen, polyphosphates, and phosphate. Amer. J. Physiol. 200: 1296-1300 (1961).

Flores, M., M. Norgard, D. Heinegard, F. P. RheinHOLT and G. ANDERsson: RGD-directed attachment of isolated rat osteoclasts to osteopontin, bone sialoprotein and fibronectin. Exp. Cell Res. 201: 526-530 (1992).

Gerber, H. P., T. H. Vu, A. M. Ryan, J. Kowalski, Z. WERB and N. Ferrara: VEGF couples hypertrophic cartilage remodeling ossification and angiogenesis dur ing endochondral bone formation. Nature Med. 5: 623 628 (1999).

Hunter, G. K. and H. A. Goldberg: Nucleation of hydroxyapatite by bone sialoprotein. Proc. Nat. Acad. Sci. USA 90: 8562-8565 (1993).

HyNES, R. 0.: Integrins: Versatility, modulation and signaling in cell adhesion. Cell 69: 11-25 (1992).

Irie, K., S. Zalzal, H. OzaWA, M. D. McKeE and A.
NANCI: Morphological and immunocytochemical characterization of primary osteogenic cell cultures derived from fetal rat cranial tissue. Anat. Rec. 252: 554-567 (1998).

LIAW, L. and H. C. CRAWford: Functions of the extracellular matrix and matrix-degrading proteases during tumor progression. Brazil. J. Med. Biol. Res. 32: 805-812 (1999).

Mark, M. P., W. T. Butler, C. W. Prince, R. D. FinKLEMAN and J.-V. RUCH: Developmental expression of 44-kDa phosphoprotein (osteopontin) and bone-carboxyglutamic acid (Gla)-containing protein (osteocalcin) in calcifying tissues of rat. Differentiation 37: 123-136 (1988).

Matsuzawa, T. and H. C. Anderson: Phosphatase of epiphyseal cartilage studied by electron microscopic cytochemical methods. J. Histochem. Cytochem. 19: 801-808 (1971).

Maximow, A. A.: Untersuchungen über Blut und Bindegewebe. III. Die embryonale Histogenese des Knochenmarks der Säugetiere. Arch. Mikrosk. Anat. 76: 1-113 (1910).

MCKEE, M. D. and A. NANCI: Post-embedding colloidalgold immunocytochemistry of noncollagenous extracellualr matrix proteins in mineralized tissues. Microsc. Res. Tech. 31: 44-62 (1995).

: Osteopontin at mineralized tisue interfaces in bone teeth and osteointegrated implants: Ultrastructural distribution and implications for mineralized tissue formation, turnover and repair. Microsc. Res. Tech. 33: 141-164 (1996).

McKee, M. D., M. C. Farach-Carson, W. T. Butler, P. V. HAUSCHKA and A. NANCI: Ultrastructural immunolocalization of noncollagenous (osteopontin and osteocalcin) and plasma (albumin and $\alpha 2 \mathrm{HS}$-glycoprotein) proteins in rat bone. J. Bone Miner. Res. 8: 485-496 (1993).

Morris, D. C., K. Masuhara, K. TaKaoka, K. Ono and H. C. ANDERson: Immunolocalization of alkaline phosphatase in osteoblasts and matrix vesicles of human fetal bone. Bone Miner. 19: 287-298 (1992).

Nakase, T., K. Takaoka, K. Hirakawa, S. Hrrota, T. Takemura, H. Onoue, K. Takebayashi, Y. Kitamura and S. Nomura: Alterations in the expression of osteonectin, osteopontin and osteocalcin mRNAs during the development of skeletal tissues in vivo. Bone Miner. 26: 109-122 (1994).

Oldberg, A., A. Franzen and D. Heinegrad: Cloning and sequence analysis of rat bone sialoprotein (osteopontin) cDNA reveals an Arg-Gly-Asp cell binding sequence. Proc. Nat. Acad. Sci. USA 87: 9995-9999 (1986)

Pinero, G. J., C. M. Farach, R. E. Devoll, J. E. Aubin, J. C. BrunN and W. T. Butler: Bone matrix proteins in osteogenesis and remodeling in the neonatal rat mandible as studied by immunolocalization of osteopontin, bone sialoprotein, alpha $2 \mathrm{HS}$-glycoprotein and alkaline phosphatase. Arch. Oral Biol. 40: 145-155 (1995). 
Reinholt, F. P., K. Hultenby, A. Oldberg and D. Heinegard: Osteopontin-a possible anchor of osteoclasts in bone. Proc. Nat. Acad. Sci. USA 87: 4473-4475 (1990).

Robinson, R.: The possible significance of hexosephosphoric esters in ossification. Biochem. J. 17: 286-293 (1923).

Ross, F. P., J. Chappel, J. I. Alvarez, D. Snader, W. T. Butler, M. C. Farac-Carson, K. A. Mintz, P. G. Robey, S. L. Teitelbaum and D. A. Chertesh: Interactions between the bone matrix protein osteopontin and bone sialoprotein and osteoclast integrin $\alpha \mathrm{V} \beta 3$ potentiate bone resorption. J. Biol. Chem. 268: 99019907 (1993).

Shijubo, N., T. Uede, S. Kon, M. Maeda, T. Segawa, A. IMADA, M. Hirasawa and S. ABE: Vascular endothelial growth factor and osteopontin in stage I lung adenocarcinoma. Amer. J. Respir. Critic. Care Med. 160: 12691273 (1999).

Takahashi, R.: Electron microscopic study of the osteogenic cells in alveolar bone of rat, with special reference to the localization of alkaline and acid phosphatase activity. (In Japanese). Shikagakuho 72: 14271467 (1972).

Prof. Hidehiro OzAWA

Department of Oral Anatomy

Niigata University Faculty of Dentistry

5274, 2-Bancho, Gakko-cho Dori

Niigata, 951-8514 Japan

Te1: +81-25-227-2814

Fax: +81-25-227-0804

E-mail: ozawa@dent.niigata-u.ac.jp

小澤 英 浩

951-8514

新潟市学校町通り $2-5274$

新潟大学歯学部

口脘解剖学第一講座 